\title{
Reproductive and obstetric outcomes in mosaic Turner's Syndrome: a cross-sectional study and review of the literature
}

\author{
Emek Doğer ${ }^{1 *}$, Yiğit Çakıroğlu', Yasin Ceylan', Esen Ulak², Özkan Özdamar ${ }^{3}$ and Eray Çalışkan ${ }^{1}$
}

\begin{abstract}
Background: Turner's syndrome (TS) is depicted as a total or partial absence of one $X$ chromosome that results in ovarian dysgenesis. Chances of spontaneous pregnancy in TS are rare and the outcome of the pregnancies is known to be poor with an increased risk of miscarriage and stillbirths. Our aim is to evaluate reproductive and obstetric outcomes of natural conception and in-vitro fertilization (IVF) cycles in mosaic TS patients.

Methods: A total of 22 mosaic TS cases (seventeen 45,X/46,XX and five 45,X/46,XX/47,XXX karyotypes) were evaluated.

Results: Live birth and abortion rates were found as $32.7 \%$ and $67.3 \%$, respectively in 52 pregnancies. Implantation, clinical pregnancy and take home baby rates were detected as $3.7 \%, 8.6 \%$ and $5.7 \%$, respectively per IVF cycle as a result of 35 cycles. Fecundability analysis revealed that $5 \%$ of the cases experienced first pregnancy within 6 months and $8 \%$ within the first 2 years. Mosaicism ratio did not have an effect on the time to the first pregnancy $(p=.149)$.

Conclusion: Only a small proportion of the mosaic TS patients conceive in the first 2 years of the marriage. Age of menarche and age of marriage appear not to have any impact on the chance of conceiving. Mosaic TS cases should counseled about the low odds of pregnancy and high miscarriage rates.
\end{abstract}

Keywords: Mosaicisim, Turner's syndrome, Obstetric outcome, Reproductive outcome

\section{Background}

Turner's syndrome (TS) is depicted as a total or partial absence of one $\mathrm{X}$ chromosome, and occurs in approximately $1 / 2200$ of live born females [1]. Nearly $43-49 \%$ of the patients are cases with classical TS who are monosomic for $\mathrm{X}$ chromosome $(45, \mathrm{X})$. The remaining patients are mosaic cases carrying normal and abnormal cell lines together (most of them had 45,X/46, XX karyotype) (15-23\%), those with isochromosome in long arm of $\mathrm{X}$ chromosome $(\mathrm{i}(\mathrm{Xq})$ ) (14 \%), those with ring $\mathrm{X}$ chromosome $(\mathrm{r}(\mathrm{X}))$ (3-11 \%) and those with 46,XX karyotype but having partial losses in one $\mathrm{X}$ chromosome $(9 \%)$. Y chromosome fragments are detected in $10-11 \%$ of the cases [2-6].

Patients with classical TS demonstrate characteristic clinical features such as short stature, web neck,

\footnotetext{
* Correspondence: emekdoger@hotmail.com

'Department of Obstetrics \& Gynecology, Kocaeli University School of Medicine, Kocaeli, Turkey

Full list of author information is available at the end of the article
}

cardiovascular and renal abnormalities and hearing loss; and besides, gonadal dysgenesis in TS results in pubertal delay or failure, infertility and premature ovarian failure (POF) in most patients $[7,8]$. Although correlation between genotype and phenotype is not well understood, mosaic cases present milder phenotypic abnormalities compared to those with 45,X karyotype [9]. Mosaic TS patients are more likely to experience normal pubertal development, regular menstrual cycles and to conceive spontaneously compared to those with $45, \mathrm{X}$ monosomy [2]. Since mosaic patients are diagnosed following karyotype analysis due to recurrent pregnancy loss, repeated in vitro fertilization (IVF) failure and history of an abnormal offspring, our knowledge concerning reproductive and obstetric outcomes relies on case reports and case series $[4,10-12]$ and more comprehensive studies investigating the fertility outcomes of these patients.

The purpose of this study was to evaluate reproductive and obstetric outcomes of natural conception and IVF procedures in mosaic TS cases.

\section{Biomed Central}




\section{Materials and methods}

This retrospective study evaluated 706 female patients who underwent karyotyping between 2009-2013 in the laboratory of Medical Genetics Department of our tertiary health institution. The approval from the local ethics committee had been obtained prior to the initiation of the study. Informed consent from all individual participants included was obtained. Chromosomal analysis was performed by G-banding technique at high resolution. A hundred metaphases were counted for each patient and International System for Human Cytogenetic Nomenclature (ISCN, 2009) guidelines were used when performing karyotype analysis [13].

Mosaicism ratios of the cases were calculated by proportioning total number of abnormal cell lines. In karyotype analysis, mosaic cell line ratio of $\leq \% 10$ was defined as lowgrade mosaicism, and > \%10 as high-grade mosaicism [14].

Medical history regarding prior hormone therapy, prior assisted reproductive techniques attempts in infertility cases, obstetric outcomes in patients who had conceived through spontaneous or IVF cycles and perinatal outcomes were obtained by face-to-face interview or assessment of hospital medical records. All patients were assessed with physical examination and underwent a set of diagnostic tests including thyroid function tests, abdominal ultrasonography and echocardiography.

\section{Statistical analysis}

SPSS version 15.0 (Statistical Package for Social Science, Spss Inc. Chicago, IL, USA) was used for statistical analysis. Parametric variables were given as median (range), mean \pm standard deviation or \pm standard error. Chi-square test was used for the comparison of parametric variables. Non-parametric tests such as Mann-Whitney U test was used to compare non-parametric variables between cases with high-grade mosaicisim and low-grade mosaicism. Possibility of a total of 2-year fecundability was calculated at 6-month intervals by time-table analysis. The effect of menarche age, marriage age and mosaicism ratio on the time until spontaneous or IVF pregnancy was assessed by Cox-regression analysis. $\mathrm{p}<0.05$ was considered as statistically significant.

\section{Results}

A total of 22 mosaic TS patients were extracted from 706 patients who underwent genetic karyotyping for varying indications including, recurrent implantation failure $(5.1 \%)$, recurrent pregnancy loss (defined as three or more consecutive miscarriage) (2.2\%), POF (2.2 \%) and history of an offspring with any chromosomal or structural abnormality (4\%). Clinical characteristics of our study population were presented in Table 1. Menarche was achieved with hormone replacement therapy in three cases at the ages of 16,17 and 18 years and
Table 1 Clinical characteristics of the study group

\begin{tabular}{|c|c|}
\hline Patients age at the time of enrollment (years) ${ }^{a}$ & $37(26-47)$ \\
\hline Patients age at the time of diagnosis (years) ${ }^{a}$ & $34.5(18-46)$ \\
\hline Age of menarche (years) ${ }^{a}$ & $13(11-18)$ \\
\hline Age at marriage (years) ${ }^{a}$ & $25(15-40)$ \\
\hline Patients age at first pregnancy (years) $)^{a, b}$ & $23(18-32)$ \\
\hline $\begin{array}{l}\text { Time from the marriage to the first conception } \\
\text { (months) })^{a, b}\end{array}$ & $12(6-49)$ \\
\hline Height of the patients $(\mathrm{cm})^{a}$ & $163(132-174)$ \\
\hline Body mass index at the enrollment $\left(\mathrm{kg} / \mathrm{m}^{2}\right)^{c}$ & $28.43 \pm 1.21$ \\
\hline
\end{tabular}

continued regularly. Menstruation was regular in 18 cases at the time of study enrollment whereas it was irregular in the two and the remaining two, who were diagnosed as POF at the ages of 28 and 38, were on hormone replacement therapy. There was one case with a short stature $(<150 \mathrm{~cm})$ phenotype and no cases with cardiovascular or renal abnormality, hearing loss and mental retardation among the included patients. The following systemic disorders were diagnosed in the patients; hypothyroidism in three, type 2 diabetes in three, asthma in one and generalized anxiety disorder in one patients. Uterine hypoplasia was observed in one case. In addition, one patient underwent hysteroscopic septum resection for uterine septum, another case underwent Strasmann metroplasty for bicornuat uterus and one underwent hysteroscopy and cavity expansion with fundal and lateral incisions for T-shaped uterus.

A total of 22 female patients, who were diagnosed as mosaic TS after karyotyping and who attended our IVF clinic with the diagnoses of recurrent implantation failure $(n=10)$, recurrent pregnancy loss $(n=9)$, infertility due to POF $(n=1)$, and history of a prior offspring with a chromosomal abnormality $(n=2)$, were included in the study. Out of 22 patients, five despite IVF treatment and one who never sought treatment, could not ever conceive. Out of remaining 16 cases, 11 conceived spontaneously and five conceived following IVF cycles; resulting in a total of 52 pregnancies of which 17 $(32.7 \%)$ resulted in live birth and $35(67.3 \%)$ resulted in abortion.

Of 22 mosaic TS patients' karyotypes, 17 were 45,X/ $46, \mathrm{XX}$ and five were $45, \mathrm{X} / 46, \mathrm{XX} / 47, \mathrm{XXX}$. There were no cases including 45, $\mathrm{X} / 46, \mathrm{Xr}(\mathrm{X}) ; 45, \mathrm{X} / 46, \mathrm{X}(\mathrm{i}(\mathrm{Xq}))$; $\mathrm{Y}$ chromosome fragment or 46,XX karyotype with structural abnormalities in $\mathrm{X}$ chromosome. One patient was determined to have 45,X/46,XX inv(9)p11q13 karyotype. The comparison regarding the number and the percentages of pregnancies, miscarriages and live births between the different karyotypes of TS were presented in Table 2. 
Table 2 Comparison of the ratios of live birth and miscarriage or terminated fetus between groups

\begin{tabular}{lclcc}
\hline Maternal karyotype & $\begin{array}{l}45, X / 46, X X \\
(n=17)\end{array}$ & $\begin{array}{l}45, X / 46, X X / 47, X X X \\
(n=5)\end{array}$ & $\begin{array}{l}\text { All cases } \\
(n=22)\end{array}$ & $p$ \\
\hline No of pregnancies $(n)$ & 35 & 17 & 52 & .678 \\
Live birth $(n(\%))$ & $10(28.6)$ & $7(41.2)$ & $17(32.7)$ & .611 \\
Miscarriage $(n(\%))$ & $25(71.4)$ & $10(58.8)$ & $35(67.3)$ & .712 \\
\hline$p<.05$ Statistically significant & & &
\end{tabular}

Mosaic cell line ratio was below $10 \%$ in 17 and above $10 \%$ in five cases. The comparison regarding the number and the percentages of pregnancies, miscarriages and live births between high-grade and low-grade mosaicism cases were presented in Table 3. Miscarriages included 29 spontaneous abortions, four biochemical abortions and two induced abortions (due to anencephaly and trisomy 21). Mean abortion week was found to be $8.16 \pm 2.98( \pm S D)$ in cases who experienced spontaneous abortion (Biochemical abortions were excluded from the calculation).

A total of 82 embryo transfers were performed on 10 patients during 35 intracytoplasmic sperm injection (ICSI) treatment cycles. Five patients could not conceive despite ICSI and five cases could conceive following ICSI treatment. Out of these pregnancies, one clinical pregnancy resulted in spontaneous abortion, two pregnancies resulted in biochemical abortion and two live babies were taken home. Implantation rate per cycle was $3.7 \%$ (3/82), clinical pregnancy rate was $8.6 \%(3 / 35)$ and take home baby rate was $5.7 \%(2 / 35) .90 .4 \%$ of the pregnancies $(n=47)(88.2 \%$ of live born babies $(n=15))$ have occurred in spontaneous cycles.

Perinatal outcomes of the 17 pregnancies that resulted in live birth are presented in Table 4. Mean birth weight of these newborns was found as $3355 \pm 140 \mathrm{gr}( \pm \mathrm{SE})$.

Prenatal or postnatal cytogenetic examination was performed in three pregnancies, two as prenatal and one as postnatal investigations. Out of two prenatal cytogenetic examinations, one patient was diagnosed as Trisomy 21 and subsequently underwent a pregnancy termination; whereas the other revealed a normal karyotype. The postnatal investigation was of a patient who underwent karyotype analysis at the age of 15 due to mental retardation and a deletion was detected between the regions of $18 \mathrm{q} 21.3$ and q23. None of the miscarriages were evaluated genetically from the abortus materials.
Time table analysis revealed that pregnancy hazard rate within the first 2 years at 6-month intervals was found to be 0.01 in the first 6 months, 0.04 in the second 6 months, 0.02 in the third 6 months and 0.01 in the last 6 months. Neither spontaneous nor IVF pregnancy was detected beyond 60th month of marriage. COX regression analysis revealed that marriage age, menarche age and mosaicism ratio did not have an effect on the time until first pregnancy $(p=.685 ; p=.350$ and $p=.149$, respectively).

\section{Discussion}

Gonadal dysgenesis in women with Turner Syndrome might depend on chromosome pairing failure during meiotic prophase, causing failure in synaptic formation at the zygotene and oocyte loss [15]. Majority of germ cells, which trigger spontaneous puberty in 10-30\% and provide pubertal development, start to diminish in the third month of intrauterine life, resulting in only 5-10\% of affected patients could menstruate regularly [16-19]. POF is another frequent clinical feature of TS and mean age of menopause was reported to be 29.3 years [18]. However; the degree of gonadal dysgenesis depends on the size of impaired regions of homologous chromosomes. Severe pairing failures induce the degeneration of all oocytes prior to puberty and are associated with rimary amenorrhea and poor sexual development, whereas mild pairing failures contribute to the survival of a considerable number of oocytes until puberty, leading to secondary amenorrhea and secondary impaired sexual development [15]. Thus, it is possible that puberty and reproductive capacities are less affected or even preserved in TS cases with mosaic karyotype [19]. When compared to the classical form, mosaic karyotype TS cases are more likely to present spontaneous puberty, normal levels of serum sex steroids and gonadotropins and follicles in ovarian biopsies [20]. In addition, the chance of spontaneous conceiving in women with TS was reported as 2-10\%, most of which are the cases of mosaic pattern and those with $45, \mathrm{X}$ monosomy are candidates for oocyte donation [16, 21, 22].

$\mathrm{X}$ chromosome monosomy and mosaicism are encountered in $1.5 \%$ of all amenorrhea cases although the incidence of $\mathrm{X}$ chromosome mosaicism in the general population still remains challenging [23]. In our study, we detected mosaic Turner karyotype in $2.2 \%$ of the

Table 3 Comparison of the ratios of live birth and miscarriage or terminated fetus between low and high grade mosaic cell line groups

\begin{tabular}{|c|c|c|c|c|}
\hline Mosaic cell line ratio & $\begin{array}{l}\text { Cases with low grade } \\
\text { mosaic cell line }(n=17)\end{array}$ & $\begin{array}{l}\text { Cases with high grade } \\
\text { mosaic cell line }(n=5)\end{array}$ & All cases $(n=22)$ & $p$ \\
\hline No of Pregnancies (n) & 46 & 6 & 52 & .062 \\
\hline Miscarriage (n (\%)) & $30(65.2)$ & $5(83.3)$ & $35(67.3)$ & .468 \\
\hline Live Birth (n (\%)) & $16(34.8)$ & $1(16.7)$ & $17(32.7)$ & .127 \\
\hline
\end{tabular}

$p<.05$ Statistically significant 
Table 4 Perinatal outcomes of the pregnancies that resulted in live birth

\begin{tabular}{lcc}
\hline & Number & Percentage \\
\hline Route of delivery & 9 & $52.9 \%$ \\
Vaginal & 8 & $47.1 \%$ \\
Abdominal (C/S) & & \\
Fetal gender & 12 & $70.6 \%$ \\
Female & 5 & $29.4 \%$ \\
Male & & \\
Adverse perinatal outcomes & 1 & $5.9 \%$ \\
IUGR & 1 & $5.9 \%$ \\
P.previa & 2 & $11.8 \%$ \\
GDM &
\end{tabular}

$\mathrm{C} / \mathrm{S}$, cesarean section; IUGR, intrauterine growth restriction; P.previa, placenta previa; GDM, gestational diabetes mellitus

cases with a diagnosis of recurrent pregnancy loss and $5.1 \%$ of the cases with recurrent implantation failure. Our study results are compatible with the previously published reports which indicated the rate of mosaic Turner karyotype in the recurrent pregnancy loss groups as $2.6 \%$ [24]. X chromosome mosaicism ratio in female partner of ICSI candidate couples was reported to be 2.77-4.12\% whereas 45X/46XX mosaicism in couples with IVF failures due to severe male infertility and fertilization failures were reported to be 3.5-9.6 \% [25-28]. Simpson et al. suggested that mosaicism has been underestimated as a cause of repeated failure in assisted reproduction [29].

The median age of marriage was 25 (15-40) and median age of first pregnancy in spontaneously pregnant women was 23 years $(18-32)$ and these results are in agreement with the previous studies reporting median age of first pregnancy in TS syndrome cases as 23.527.2 years $[4,10]$. ROC analysis revealed that marriage age had no impact on the chance of conceiving. Moreover, Cox-regression analysis demonstrated that the age of menarche, age of marriage and mosaicism ratio did not affect the time-to-first pregnancy. There were no significant difference between high-grade and low-grade mosaicism cases in terms of pregnancy, time-to-first spontaneous pregnancy, abortion and take home baby rates in our study. Several previously published reports indicated a correlation between mosaicism ratio and phenotypic abnormalities and reproductive capacity of the patients; on the contrary, some other publications did not find a consistent relationship [2, 30]. Scholtes et al. showed a correlation between mosaicism and a low implantation rate [31]. In contrast, Sonntag et al. could not find any significant impact of low-grade mosaicism on the course or outcome of ICSI in 20 couples [14]. No required minimum percentage of abnormal cells has been established to define true versus "low-grade" mosaicism. Thus, some studies disregard the importance of low-grade mosaicism [26]. In our study, first two-year fecundability analyses revealed that $5 \%$ of the cases experienced their first pregnancy within 6 months and $8 \%$ within first 2 years. No pregnancy was detected after 60 months of marriage. With the expectation of reduction in ovarian reserve with advanced age in TS, our results revealed that chance of fertility in cases with mosaic karyotype was high at younger ages but their chance will decrease if they do not conveive within the first 2 years.

Majority of TS cases who conceive spontaneously are known to have mosaic cell lines. In the study by Birkebaek et al., evaluating 410 Danish women with TS, 27 out of 31 women who could spontaneously conceive, at least once, had a TS diagnosis [4]. Similarly in the study by Bryman et al. there were $45, \mathrm{X} / 46, \mathrm{XX}$ mosaicism in 25 out of 27 Swedish women with TS. While 23 cases had a spontaneous pregnancy, three cases conceived by assisted reproductive technologies [32]. Clinical pregnancy rate and implantation rate were reported to be $46 \%$ and $30 \%$, respectively, by fresh embryo transfer in oocyte donation cycles, and $28 \%$ and $19 \%$, respectively, in frozen embryo transfers in TS cases [33]. Pregnancy rates of these cases were found to be comparable with other women in donation programs or probably lower due to diminished endometrial receptivity $[34,35]$.

Many studies have shown that TS women who are able to conceive are at increased risk for miscarriage, stillbirths and malformed babies [7, 10, 36, 37]. Tarani et al. analyzed 160 spontaneous pregnancies in 74 women with TS and reported that $67.3 \%$ of the pregnancies with $45, \mathrm{X} / 46, \mathrm{XX}$ karyotype and $70.8 \%$ of the pregnancies with $45, \mathrm{X} / 46, \mathrm{XX} /$ 47,XXX karyotype resulted in miscarriage or malformed fetus [10]. Similarly, Bryman et al. have reported that $45 \%$ of cases with mostly $45, \mathrm{X} / 46, \mathrm{XX}$ mosaicism who conceived with their own oocytes ended with miscarriage and $10 \%$ of them with induced abortion [32]. Moreover, Kuo et al. have reported miscarriage rate as $68.6 \%$ in patients with diminished ovarian reserve and $44.1 \%$ in patients without diminished ovarian reserve among cases who had a history of prior recurrent spontaneous abortions with $\mathrm{X}$ chromosome mosaicism [38]. Among our patients, $67.3 \%$ of the pregnancies were resulted in abortion or termination. However karyotyping was performed for nine cases in our study group due to recurrent pregnancy loss. This condition was a reason of how we detected a high abortion rate and besides, this rate is quite higher than the abortion rate of $10-15 \%$ in the population [39].

Miscarriages that are frequently seen in TS cases are explained by chromosomal abnormalities in fetus, autoimmune disorders, ovarian and uterine factors $[10,11$, $38,40]$. Aborted fetuses of TS women or their live born children are more susceptible to trisomy 21 (4\% vs $0.4 \%$, respectively) and TS (15\% vs $0.5 \%$, respectively) 
risks compared to general population [10]. Hereditary in nature was reported in mosaic TS cases and especially cases with ring chromosome [10, 41]. Singh et al. revealed in their study investigating 97 conceptions in 31 pregnant women with sex chromosome mosaicism that $75 \%$ of the fetuses were abnormal and $50 \%$ of these pregnancies were resulted in spontaneous abortion and $25 \%$ had genetic or congenital abnormalities [42]. Besides, it was reported that abnormal karyotype ratio was increased from $42.9 \%$ up to $73.7 \%$ in abortion samples in the presence of diminished ovarian reserve [38]. Birkebaek et al. detected chromosomal aberrations in 6 of 25 pregnancies who underwent prenatal or postnatal cytogenetic analysis among TS cases with classical and mosaic forms [4]. In our study fetal karyotype analysis was not performed in all pregnancies terminated by abortion, hence the exact abnormality rates cannot be predicted however it seems likely to be higher. Cerebral paresis, neuropsychological disorder, aortic coarctation, cleft lip and palate and congenital tumor were detected in 5 (7\%) of 68 children born to women with TS [32]. Even mosaic, preimplantation diagnosis, chorionic villus sampling or amniocentesis should be recommended for the patients undergoing infertility treatment if pregnancy is planned with their own oocytes since biological children of TS women are under risk for chromosomal abnormalities; and their children should be investigated for birth defects after delivery.

Uterine hypoplasia and related reduced uterine perfusion secondary to significant changes in utero-ovarian vascular anatomy, and subclinical uterine abnormalities in TS cases have been implicated in the etiology of miscarriages $[33,38,43]$. Although abortion rate is higher in pregnant women conceived with their own oocytes, use of donor oocytes does not reduce pregnancy loss rate in mosaic TS cases who underwent IVF ( $45 \%$ with their own oocytes vs 26-30\% with donor oocytes) [32, 44]. This condition can be suggested as the evidence of the effect of diminished endometrial receptivity as well as oocyte-associated factors in TS cases. In our study group, uterus hypoplasia was present in one case and surgery-corrected uterine abnormality was present in three cases. It has been reported that uterine size were often normal in cases with mosaic karyotype and that they experience spontaneous puberty $[45,46]$. Khastgir et al. have reported bicornuat uterus in four $(13.8 \%)$ of 29 TS cases, 10 of whom had mosaic karyotypes and miscarriage rate associated with uterus hypoplasia, bicornuat uterus and low fertilization rate was $50 \%$ [34]. Kuo et al. have reported that they detected uterine abnormality in $16.7 \%$ of mosaic X-chromosome aneuploidies with a history of recurrent spontaneous abortions and $5.2 \%$ in the control group [38]. In our study, we found the ratio of Mullerian abnormality in all mosaic TS cases as $13.6 \%$ and all pregnancies had terminated with abortions before the surgical corrections of the malformations. However, after the surgical corrections, four pregnancies were achieved and three terminated with delivery. These results suggest that the rate of uterine abnormalities in TS cases is high and that they may benefit from the surgery.

TS patients may experience complications during pregnancy due to congenital malformations and endocrine diseases, and should be evaluated for the presence of these pathologies before IVF or pregnancy [7]. Gestational diabetes mellitus was present in two $(11.8 \%)$ of 17 pregnancies that achieved live birth. These rates are close to those reported by Bryman et al. who affirmed a pregnancy induced hypertension and gestational diabetes rate of $5 \%$ in TS cases, similar to the rate in general population [32, 47, 48]. In our study population, there was one pregnancy with a history of SGA fetus delivery $(5.9 \%)$ and none of the cases had preterm delivery. In TS, preterm delivery rate was reported between 8-37.1 \% and low birth weight was between 8.8-27.5\% $[49,50]$. Given that the chromosomal aberrations arise possibly from the transmission of the imbalances in the genetic arrangements in mother to the offsprings (10), genetic counseling should be offered to all who conceived with autologous oocytes (11). Preimplantation genetic diagnosis (PGD) may improve the chance of conceiving in patients with recurrent ART failure and TS (12).

Limitations of our study include its retrospective design, presence of some data that are based on patients' memory, absence of a control group and inability to perform a karyotype analysis in all newborns. In the context of lack of a control group, we should emphasize that it was not possible to constitute a control group since the present was not a population-based study. In addition, it is obvious that it is difficult to conduct such a study in this issue in a prospective fashion. Besides, maternal age significantly affects gains and losses in sex chromosomes [51-53]. A significant correlation was reported between maternal age and incidence of 45, $\mathrm{X}$ cell after 51 years old, and incidence of 45 , X cell was reported to be 3.2$5.1 \%$ among the women older than this age $[52,54]$. Although cases in our study were younger than 46 years old, mosaicism ratio in some cases, whose pregnancy age was young but diagnosis age was advanced, may not reflect exact karyotype profile. Moreover, in the study by Hanson et al. percentage of cases with mosaic karyotype was found to be $45 \%$ only with karyotyping but it reached to $70 \%$ when FISH was used [3]. Mosaicism ratio was given by the assessment of 100 metaphase plaques in all cases in our study, and it should be considered that FISH method was not used while evaluating our results. Last, the results obtained in the present study might have been affected by the non-mosaicism- 
related individual factors given that some patients included had more than one pregnancy as we stressed that 16 cases experienced 52 pregnancies.

\section{Conclusion}

Only a small proportion of the mosaic TS patients conceive in the first 2 years of marriage, hence any possible interventions should be considered within this period and at as much younger ages as possible. In TS patients who conceived, only $5.7 \%$ take home baby whereas $67.3 \%$ abort. Age of menarche and age of marriage appear not to have any impact on the chance of conceiving. Mosaicism ratio does not affect the time to the first pregnancy. Patients should be informed about high abortion rates after pregnancy.

\section{Abbreviations}

TS: Turner's Syndrome; IVF: In Vitro Fertilization; ICSI: Intra Cytoplasmic Sperm Injection; FISH: Fluorescent In Situ Hybridization.

\section{Competing interests}

This research received no specific grant from any funding agency in the public, commercial or not-for-profit sectors. The authors stated that there are no conflicts of interest regarding the publication of this manuscript. The authors also state that they have had full control of all primary data and that they agree to allow the Journal to review their data if requested.

\section{Authors' contribution}

ED conceived of the study, participated in the design, obtained the data and drafted the manuscript. YÇ participated in the design, obtained the data. YC participated in the design, obtained the data, performed the statistical analysis. EU carried out the genetic analysis. ÖÖ participated in the design and drafted the manuscript. EC performed the statistical analysis and edited the manuscript. All authors read and approved the final manuscript.

\section{Author details}

${ }^{1}$ Department of Obstetrics \& Gynecology, Kocaeli University School of Medicine, Kocaeli, Turkey. ${ }^{2}$ Department of Medical Genetics, Kocaeli University School of Medicine, Kocaeli, Turkey. ${ }^{3}$ Department of Obstetrics \& Gynecology, Golcuk Military Hospital, Kocaeli, Turkey.

Received: 12 March 2015 Accepted: 28 May 2015

Published online: 10 June 2015

\section{References}

1. Hook EB, Warburton D. Turner syndrome revisited: review of new data supports the hypothesis that all viable $45, \mathrm{X}$ cases are cryptic mosaics with a rescue cell line, implying an origin by mitotic loss. Hum Genet. 2014;133:417-24.

2. El-Mansoury M, Barrenäs ML, Bryman I, Hanson C, Larsson C, Wilhelmsen L, et al. Chromosomal mosaicism mitigates stigmata and cardiovascular risk factors in Turner syndrome. Clin Endocrinol (Oxf). 2007;66:744-51.

3. Hanson L, Bryman I, Barrenäs ML, Janson PO, Wahlström J, AlbertsonWikland K, et al. Genetic analysis of mosaicism in 53 women with Turner syndrome. Hereditas. 2001;134:153-9.

4. Birkebaek NH, Crüger D, Hansen J, Nielsen J, Bruun-Petersen G. Fertility and pregnancy outcome in Danish women with Turner syndrome. Clin Genet. 2002:61:35-9.

5. Yuge A, Takai N, Nishida Y, Narahara H, Miyakawa I. Spontaneous pregnancy in a 45, X/46, X, r (X) Turner's mosaic patient. Acta Obstet Gynecol Scand. 2003;82:775-6.

6. Hennekam RCM, Krantz ID, Allanson JE. Turner syndrome. In Gorlin's syndromes of the head and neck. Oxford: Oxford University Press; 2010.

7. Hovatta O. Pregnancies in women with Turner's syndrome. Ann Med. 1999;31:106-10

8. Lippe B. Turner syndrome. Endocrinol Metab Clin North Am. 1991;20:121-52. Review.
9. Davenport ML. Approach to the patient with Turner syndrome. J Clin Endocrinol Metab. 2010;95:1487.

10. Tarani L, Lampariello S, Raguso G, Colloridi F, Pucarelli I, Pasquino AM, et al. Pregnancy in patients with Turner's syndrome: six new cases and review of literature. Gynecol Endocrinol. 1998;12:83-7. Review.

11. Abir R, Fisch B, Nahum R, Orvieto R, Nitke S, Ben RZ. Turner's syndrome and fertility: current status and possible putative prospects. Hum Reprod Update. 2001;7:603-10. Review.

12. Onalan G, Yilmaz Z, Durak T, Sahin Fl, Zeyneloglu HB. Successful pregnancy with preimplantation genetic diagnosis in a woman with mosaic Turner syndrome. Fertil Steril. 2011;95(5):1788-e1-3.

13. Shaffer LG, Slovak ML, Campbell LJ. An International System for Human Cytogenetic Nomenclature (ISCN-2009) Basel. Switzerland: Karger; 2009.

14. Sonntag B, Meschede D, Ullmann V, Gassner P, Horst J, Nieschlag E, et al. Low-level sex chromosome mosaicism in female partners of couples undergoing ICSI therapy does not significantly affect treatment outcome. Hum Reprod. 2001;16:1648-52.

15. Ogata T, Matsuo N. Turner syndrome and female sex chromosome aberrations: deduction of the principal factors involved in the development of clinical features. Hum Genet. 1995;95:607-29. Review.

16. Hovatta O. Ovarian function and in vitro fertilization (IVF) in Turner syndrome. Pediatr Endocrinol Rev. 2012;9 Suppl 2:713-7.

17. Cabanes L, Chalas C, Christin-Maitre S, Donadille B, Felten ML, Gaxotte V, et al. Turner syndrome and pregnancy: clinical practice. Recommendations for the management of patients with Turner syndrome before and during pregnancy. Eur J Obstet Gynecol Reprod Biol. 2010;152:18-24.

18. Reindollar RH, Novak M, Tho SP, McDonough PG. Adult-onset amenorrhea: a study of 262 patients. Am J Obstet Gynecol. 1986;155:531-43.

19. Campagne ME. Llamazares RC [Spontaneous puberty and menarche in a patient with Turner syndrome and 45X monosomy]. An Pediatr (Barc). 2009;70:200-2

20. Borgström B, Hreinsson J, Rasmussen C, Sheikhi M, Fried G, Keros V, et al. Fertility preservation in girls with turner syndrome: prognostic signs of the presence of ovarian follicles. J Clin Endocrinol Metab. 2009;94:74-80.

21. Sybert VP. Phenotypic effects of mosaicism for a 47, XXX cell line in Turner syndrome. J Med Genet. 2002;39:217-20.

22. Bouchlariotou S, Tsikouras P, Dimitraki M, Athanasiadis A, Papoulidis I, Maroulis G, et al. Turner's syndrome and pregnancy: has the 45, X/47, XXX mosaicism a different prognosis? Own clinical experience and literature review. J Matern Fetal Neonatal Med. 2011:24:668-72.

23. Demirhan O, Tanrıverdi N, Tunç E, Inandıklıŏlu N, Süleymanova D. Frequency and types of chromosomal abnormalities in Turkish women with amenorrhea. J Pediatr Adolesc Gynecol. 2014;27:274-7.

24. Gonçalves RO, Santos W, Sarno M, Cerqueira BA, Gonçalves MS, Costa OL. Chromosomal abnormalities in couples with recurrent first trimester abortions. Rev Bras Ginecol Obstet. 2014;36(3):113-7.

25. Gekas J, Thepot F, Turleau C, Siffroi JP, Dadoune JP, Briault S, et al. Association des Cytogeneticiens de Langue Francaise. Chromosomal factors of infertility in candidate couples for ICSI: an equal risk of constitutional aberrations in women and men. Hum Reprod. 2001;16:82-90.

26. Peschka B, Leygraaf J, Van der Ven K, Montag M, Schartmann B, Schubert R, et al. Type and frequency of chromosome aberrations in 781 couples undergoing intracytoplasmic sperm injection. Hum Reprod. 1999;14:2257-63.

27. Meschede D, Lemcke B, Exeler JR, De Geyter C, Behre HM, Nieschlag E, et al. Chromosome abnormalities in 447 couples undergoing intracytoplasmic sperm injection-prevalence, types, sex distribution and reproductive relevance. Hum Reprod. 1998;13:576-82.

28. Homer L, Morel F, Gallon F, Le Martelot MT, Amice V, Kerlan V, et al. Does $45, X / 46, X X$ mosaicism with 6-28 \% of aneuploidy affect the outcomes of IVF or ICSI? Eur J Obstet Gynecol Reprod Biol. 2012;163:47-51.

29. Simpson JL. Disorders of sex chromosomes and sexual differentiation. In: Simpson JL, Golbus MS, editors. Genetics in Obstetrics and Gynecology. Philadelphia: WB Saunders; 1992. p. 132-64.

30. Reindollar RH, McDonough PG. Delayed sexual development: common causes and basic clinical approach. Pediatr Ann. 1981;10(5):30-9.

31. Scholtes MC, Behrend C, Dietzel-Dahmen J, van Hoogstraten DG, Marx K, Wohlers S, et al. Chromosomal aberrations in couples undergoing intracytoplasmic sperm injection: influence on implantation and ongoing pregnancy rates. Fertil Steril. 1998;70:933-7. 
32. Bryman I, Sylvén L, Berntorp K, Innala E, Bergström I, Hanson C, et al. Pregnancy rate and outcome in Swedish women with Turner syndrome. Fertil Steril. 2011;95:2507-10.

33. Foudila T, Söderström-Anttila $V$, Hovatta O. Turner's syndrome and pregnancies after oocyte donation. Hum Reprod. 1999;14:532-5.

34. Khastgir G, Abdalla H, Thomas A, Korea L, Latarche L, Studd J. Oocyte donation in Turner's syndrome: an analysis of the factors affecting the outcome. Hum Reprod. 1997;12:279-85.

35. Yaron Y, Ochshorn Y, Amit A, Yovel I, Kogosowki A, Lessing JB. Patients with Turner's syndrome may have an inherent endometrial abnormality affecting receptivity in oocyte donation. Fertil Steril. 1996;65:1249-52.

36. Kaneko N, Kawagoe S, Hiroi M. Turner's syndrome-review of the literature with reference to a successful pregnancy outcome. Gynecol Obstet Invest. 1990;29:81-7.

37. Nielsen J, Wohlert M. Chromosome abnormalities found among 34,910 newborn children: results from a 13-year incidence study in Arhus Denmark. Hum Genet. 1991:87:81-3.

38. Kuo PL, Guo HR. Mechanism of recurrent spontaneous abortions in women with mosaicism of X-chromosome aneuploidies. Fertil Steril. 2004;82:1594-601.

39. 2008 Turkey Demographic and Health Survey TDHS-2008; main report: 98. http://www.hips.hacettepe.edu.tr/eng/tdhs08/ar.shtml.

40. Saenger P. Turner's syndrome. N Engl J Med. 1996;335:1749-54.

41. Blumenthal AL, Allanson JE. Turner syndrome in a mother and daughter: $r(X)$ and fertility. Clin Genet. 1997;52:187-91.

42. Singh DN, Hara S, Foster HW, Grimes EM. Reproductive performance in women with sex chromosome mosaicism. Obstet Gynecol. 1980;55:608-11.

43. Cohen MA, Sauer MV, Lindheim SR. 21-hydroxylase deficiency and Turner's syndrome: a reason for diminished endometrial receptivity. Fertil Steril. 1999;72:937-9.

44. Brezina PR, Christianson MS, Nguyen KHD, Siegel A, Benner AT, Kearns WG. Maternal XX/X chromosome mosaicism in donor oocyte in vitro fertilization (IVF). Middle East Fertil Soc J. 2012;17:129-33.

45. Rodrigues EB, Braga J, Gama M, Guimarães MM. Turner syndrome patients' ultrasound profile. Gynecol Endocrinol. 2013;29:704-6.

46. Doerr HG, Bettendorf M, Hauffa BP, Mehls O, Partsch CJ, Said E, et al. Uterine size in women with Turner syndrome after induction of puberty with estrogens and long-term growth hormone therapy: results of the German IGLU Follow-up Study 2001. Hum Reprod. 2005;20:1418-21.

47. Sibai BM, Caritis SN, Thom E, Klebanoff M, McNellis D, Rocco L, et al. Prevention of preeclampsia with low-dose aspirin in healthy, nulliparous pregnant women. N Engl J Med. 1993;329:1213-8.

48. Report of the National High Blood Pressure Education Program Working Group on High Blood Pressure in Pregnancy. Am J Obstet Gynecol. 2000;183:S1-S22.

49. Hagman A, Loft A, Wennerholm UB, Pinborg A, Bergh C, Aittomäki K, et al. Obstetric and neonatal outcome after oocyte donation in 106 women with Turner syndrome: a Nordic cohort study. Hum Reprod. 2013;28:1598-609.

50. Alvaro Mercadal B, Imbert R, Demeestere I, Englert Y, Delbaere A. Pregnancy outcome after oocyte donation in patients with Turner's syndrome and partial X monosomy. Hum Reprod. 2011;26:2061-8.

51. Nowinski GP, Van Dyke DL, Tilley BC, Jacobsen G, Babu WR, Worsham MJ, et al. The frequency of aneuploidy in cultured lymphocytes is correlated with age and gender but not with reproductive history. Am J Hum Genet. 1990;46:1101-11.

52. Jacobs PA, Brunton M, Court Brown WM, Doll R, Goldstein H. Change of human chromosome count distribution with age: evidence for a sex differences. Nature. 1963;197:1080-1.

53. Ford JH, Russell JA. Differences in the error mechanisms affecting sex and autosomal chromosomes in women of different ages within the reproductive age group. Am J Hum Genet. 1985;37:973-83.

54. Guttenbach M, Koschorz B, Bernthaler U, Grimm T, Schmid M. Sex chromosome loss and aging: in situ hybridization studies on human interphase nuclei. Am J Hum Genet. 1995;57:1143-50.

\section{Submit your next manuscript to BioMed Central and take full advantage of:}

- Convenient online submission

- Thorough peer review

- No space constraints or color figure charges

- Immediate publication on acceptance

- Inclusion in PubMed, CAS, Scopus and Google Scholar

- Research which is freely available for redistribution

Submit your manuscript at www.biomedcentral.com/submit 